\title{
Salivary and Serum Interleukin-10, C-Reactive Protein, Mean Platelet Volume, and CRP/MPV Ratio in the Diagnosis of Late- Onset Neonatal Sepsis in Full-Term Neonates
}

\author{
Ahmed Omran $\mathbb{D}^{1},{ }^{1}$ Hazem Sobh, ${ }^{1}$ Mohamed Osama Abdalla $\mathbb{D}^{2},{ }^{2}$ Sonya El-Sharkawy, ${ }^{3}$ \\ Ahmed R. Rezk $\left(\mathbb{1},{ }^{4}\right.$ and Abdelmoneim Khashana $\left(^{1}{ }^{1}\right.$ \\ ${ }^{1}$ Department of Pediatrics \& Neonatology, Faculty of Medicine, Suez Canal University, Ismailia, Egypt \\ ${ }^{2}$ Clinical Pathology Department, Faculty of Medicine, Suez Canal University, Ismailia, Egypt \\ ${ }^{3}$ Departments of Pediatrics \& Neonatology, Faculty of Medicine, Port Said University, Port Said, Egypt \\ ${ }^{4}$ Department of Pediatrics, Ain Shams University, Cairo, Egypt
}

Correspondence should be addressed to Ahmed Omran; agomran1@yahoo.com

Received 7 July 2021; Revised 7 September 2021; Accepted 24 September 2021; Published 12 October 2021

Academic Editor: Lihua Duan

Copyright (c) 2021 Ahmed Omran et al. This is an open access article distributed under the Creative Commons Attribution License, which permits unrestricted use, distribution, and reproduction in any medium, provided the original work is properly cited.

\begin{abstract}
Salivary markers could serve as potential noninvasive markers in the diagnosis of neonatal infections. We aimed to investigate the diagnostic role of salivary and serum interleukin 10 (IL-10), C-reactive protein (CRP), mean platelet volume (MPV), and CRP/MPV ratio in the diagnosis of late-onset neonatal sepsis in full-term neonates. Seventy full-term neonates were enrolled in this prospective case-control study, 35 with late-onset neonatal sepsis, and 35 controls. Salivary IL-10, serum IL-10, and CRP concentrations were measured by enzyme-linked immunosorbent assay (ELISA). Complete blood (CBC) count was measured by an automated blood cell counter. The salivary IL-10, serum IL-10, CRP, MPV, and CRP/MPV ratio levels were much higher in neonates with late-onset sepsis than in control $(220 \pm 150$ vs. $18 \pm 9 \mathrm{pg} / \mathrm{ml}, P<0.001),(316 \pm 198$ vs. $23.7 \pm$ $14 \mathrm{pg} / \mathrm{ml}, P<0.001),(78.2 \pm 34$ vs. $3.3 \pm 1.7 \mathrm{mg} / \mathrm{L}, P<0.001),(11.2 \pm 0.9$ vs. $8.6 \pm 0.4 \mathrm{fL})$, and $(7.08 \pm 3.3$ vs. $0.4 \pm 0.2, P<$ 0.001 ), respectively. At the cutoff point of $>31 \mathrm{pg} / \mathrm{ml}$, salivary IL-10 showed $97.1 \%$ sensitivity and $94.3 \%$ specificity. Serum IL-10 at a cutoff value of $\geq 33.6 \mathrm{pg} / \mathrm{ml}$ had a sensitivity of $97.1 \%$ and specificity of $80 \%$. MPV showed a sensitivity of $100 \%$ and specificity of $94.4 \%$ at a cutoff value $\geq 9.2 \mathrm{fL}$. CRP/MPV ratio showed a sensitivity of $100 \%$ and specificity of $97.1 \%$ at a cutoff value $>0.9$. Salivary and serum IL-10 showed a positive correlation with CRP and CRP/MPV ratio in septic neonates. The current study shows for the first time that both salivary IL-10 and CRP/MPV showed statistically significant differences between neonates with late-onset sepsis and controls. Accordingly, salivary IL-10 could serve as a potential noninvasive biomarker for the diagnosis of late-onset sepsis in full-term neonates.
\end{abstract}

\section{Introduction}

Despite marked improvement in neonatal care, sepsis remains an important contributor to the neonatal morbidity and mortality worldwide $[1,2]$. Neonatal sepsis can be defined both clinically and/or microbiologically as a systemic inflammatory response to infection with the production and release of a wide range of inflammatory mediators. Early detection of neonatal sepsis is still a very challenging task because of its nonspecific clinical presentation and difficulty to differentiate from noninfectious conditions $[3,4]$. The gold standard to diagnose neonatal sepsis is blood culture which may be time-consuming and has limited sensitivity.

Interleukin-10 (IL-10) is a key anti-inflammatory cytokine produced by many different kinds of immune cells and has a crucial role in preventing inflammatory and autoimmune pathologies [5-7]. The expression of anti-inflammatory cytokines including IL-10 is predominately occurring during the second phase of neonatal sepsis which reflects the upregulation of immunosuppressive mechanisms [8]. Therefore, IL- 
10 plays an important role in the early diagnosis of late-onset neonatal sepsis [9-12].

Saliva is an excellent noninvasive and easily accessible biofluid that represents an alternative to serum testing to assess and monitor critically ill neonates. Salivary biomarkers were reported to detect infections in full-term and preterm infants [13-18].

C-reactive protein (CRP) is an established marker of systemic inflammation and one of the most commonly used and extensively studied markers for the diagnosis of neonatal sepsis $[3,15,17,19]$. High mean platelet volume (MPV) is a sign of platelet activation. In clinical practice, MPV could be used as an indicator for the early diagnosis of neonatal sepsis [15, 20-23]. Several studies have examined the potential correlation between CRP and MPV values in patients with inflammatory states [24-27]. But only one study investigated the CRP/MPV ratio in children with pneumonia [28]. Various other ratios are being used in the diagnosis of neonatal sepsis, which includes CRP/albumin ratio [29], neutrophil-lymphocyte ratio [15, 30-33], and platelet to lymphocyte ratio [34].

To the best of our knowledge, this is the first study to evaluate the applicability of salivary IL-10 and CRP/MPV ratio as diagnostic markers in full-term neonates with lateonset sepsis.

\section{Materials and Methods}

2.1. Study Population. A prospective case-control study was conducted at the neonatal intensive care unit (NICU) of the Suez Canal University Hospital, Ismailia, Egypt, between January 2018 and January 2019. Thirty-five neonates with late-onset sepsis and 35 control neonates were enrolled. The protocol was approved by the Institutional Review and Research Ethics Boards of the Faculty of Medicine, Suez Canal University. Written informed consent was obtained from the parents of all neonates in the study.

Full-term neonates admitted in the NICU, who were suspected to have late-onset sepsis (onset after $72 \mathrm{~h}$ of birth), were enrolled in the study. The diagnosis of clinical sepsis was reached by history, clinical findings, laboratory findings, and blood culture. A clinical sepsis score was created based on a score defined by Töllner [35]. This included the presence of three or more of the following categories of clinical signs: (1) temperature instability (hyperthermia and hypothermia); (2) cardiovascular alterations (tachycardia, bradycardia, poor perfusion, and hypotension); (3) respiratory alterations (tachypnea, grunting, intercostal retractions, cyanosis, and apnea); (4) gastrointestinal alterations (abdominal distension and feeding intolerance); and (5) neurologic alterations (lethargy, hypotonia, and seizures).

Neonates with early-onset sepsis, preterm, and neonates with confirmed pneumonia or other inflammatory conditions, metabolic disorders, intrauterine growth restriction, CNS malformations, chromosomal abnormalities, or birth asphyxia were excluded from the study.

The controls were age- and sex-matched neonates with no clinical or laboratory findings of sepsis and were followed up in our hospital for non-infectious, unconjugated hyperbilirubinemia, and males evaluated before circumcision.

Sample size: the sample size was calculated using the following formula [36].

$$
n=\left[\frac{Z_{\alpha / 2}}{E}\right]^{2} * P(1-P) \text {, }
$$

where $n$ is the sample size. $Z_{\alpha / 2}=1.96$ is the critical value that divides the central $95 \%$ of the $Z$ distribution from the $5 \%$ in the tail. $E$ is the margin of error/width of confidence interval $=5 \% . P$ is the prevalence/proportion in the study group $=2.23 \%$ [37].

The final sample size was 70 (35 cases and 35 controls).

2.2. Saliva Collection. Salivary samples were collected at 7 am because of the independent diurnal rhythms of salivary cytokines and 1 hour before feeding to avoid milk contamination [38]. Collection of saliva was performed as mentioned in previously published researches [14, 15, 39]. After collection, samples were put in polypropylene vials to avoid contamination and analytic retention faults. Then samples were sent to the laboratory immediately and stored at $-20^{\circ} \mathrm{C}$ until batch analysis.

2.3. Laboratory Workup. For each patient, $2 \mathrm{ml}$ of venous blood was collected in ethylenediaminetetraacetic acid (EDTA) and plain tubes. EDTA samples were used for complete blood count (CBC) using the Sysmex XN-550 automatic cell counter (Sysmex Corp., Kobe, Japan). Samples were analyzed within $1 \mathrm{~h}$ after sampling to avoid platelet swelling. Blood samples collected in plain tubes were left for complete coagulation at room temperature, and then serum was separated by centrifugation at $3000 \mathrm{rpm}$ for 10 minutes. Serum CRP concentration was assessed using Cobas 6000 analyzer (Roche, Mannheim, Germany). Serum and salivary IL-10 were measured by enzyme-linked immunosorbent assay (ELISA) kit (E0056h, EIAab, Shanghai, China) according to the manufactures' instructions. All samples were collected before starting antibiotic therapy.

Blood cultures were performed for each infant with suspected sepsis at the time of admission and before antibiotic therapy. $1 \mathrm{ml}$ of blood was placed in a pediatric blood culture bottle. Cultures were done using the BacT/Alert system (BioMérieux, Durham, NC, US). Bacterial identification of positive samples was done by standardized biochemical tests, and antibiotic susceptibility was assessed according to the Clinical and Laboratory Standards Institute method.

2.4. Statistical Analysis. The statistical analysis was performed using SPSS for Windows statistical package, version 20 (SPSS, Chicago, IL, USA). The differences between groups regarding nonparametric quantitative data were assessed by Mann-Whitney $U$-test. The Chi-square test was used for testing significant differences of qualitative variables. The sensitivity, specificity, optimal serum, and salivary IL-10 cut points were determined using the receiver operating characteristic (ROC) curve. For all statistical analyses, the level of considered significance was $<0.05$. 


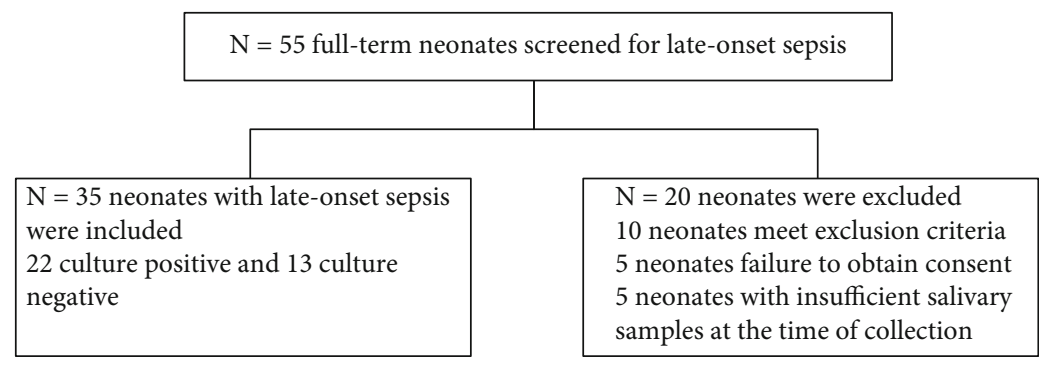

Figure 1: Patient's flow chart.

TABLE 1: Comparison of biomarkers for late-onset sepsis between septic and control neonates.

\begin{tabular}{|c|c|c|c|}
\hline & $\begin{array}{c}\text { Sepsis }(n=35) \\
\text { Mean } \pm \text { SD }\end{array}$ & $\begin{array}{c}\text { Control }(n=35) \\
\text { Mean } \pm \text { SD }\end{array}$ & $P$ value \\
\hline Total leucocyte count $\left(/ \mathrm{mm}^{3}\right)$ & $13.3 \pm 6.3$ & $12.8 \pm 4.3$ & 0.8 \\
\hline Platelet count $\left(10^{3} / \mathrm{mm}^{3}\right)$ & $152.3 \pm 201$ & $245.1 \pm 70.8$ & $0.012^{*}$ \\
\hline MPV (fL) & $11.2 \pm 0.9$ & $8.6 \pm 0.4$ & $<0.001^{*}$ \\
\hline CRP (mg/L) & $78.2 \pm 34$ & $3.3 \pm 1.7$ & $<0.001^{*}$ \\
\hline CRP/MPV ratio & $7.08 \pm 3.3$ & $0.4 \pm 0.2$ & $<0.001^{*}$ \\
\hline Serum IL-10 (pg/ml) & $316 \pm 198$ & $23.7 \pm 14$ & $<0.001^{*}$ \\
\hline Salivary IL-10 (pg/ml) & $220 \pm 150$ & $18 \pm 9$ & $<0.001^{*}$ \\
\hline
\end{tabular}

MPV: mean platelet volume; CRP: C-reactive protein; IL-10: interleukin 10.

\section{Results}

3.1. Population Characteristics, Prenatal, and Clinical Presentation. During the study period, 90 full-term neonates were included in study 55 with suspected sepsis from which only 35 matched the inclusion criteria and 35 controls (Figure 1). The mean age for sepsis and controls were $(13 \pm 6$ and $11 \pm 2)$ days, respectively, males constitute $60 \%$ of the sepsis group and $54.3 \%$ of the controls with no statistically significant difference. Regarding weight, gestational age, and mode of delivery, there were also no statistically significant differences between both groups ( $P$ value $>0.05$ )

Regarding the prenatal data, there were no statistically significant differences between both groups in the history of premature rupture of membrane (PROM), maternal fever, and maternal urinary tract infection (UTI) $(P$ value $>0.05)$.

Lethargy and temperature instability were the most presenting clinical findings in the sepsis group $(85.7 \%$ and $77.1 \%$, respectively), followed by poor perfusion and hypotension presented in $54.3 \%$, and DIC presented in $25.7 \%$.

3.2. Pathogen Distribution. Blood cultures were positive in 22 infants (62.8\%) in the sepsis group. The identified bacteria included Klebsiella pneumonia $(n=8)$, Escherichia coli $(n=5)$, Staphylococcus aureus $(n=5)$, and mixed infection $(n=4)$.

3.3. Comparison of Salivary and Serum IL-10, CRP/MPV Ratio, and Other Markers between the Two Groups. As presented in Table 1, laboratory results between the sepsis group and the control group were compared. Septic neonates had
TABLE 2: Comparison of biomarkers for late-onset sepsis between blood culture positive and negative septic cases.

\begin{tabular}{lccc}
\hline & $\begin{array}{c}\text { Culture positive } \\
(n=22)\end{array}$ & $\begin{array}{c}\text { Culture negative } \\
(n=13)\end{array}$ & $\begin{array}{c}P \\
\text { value }\end{array}$ \\
\hline MPV (fL) & $11.1 \pm 0.9$ & $11.4 \pm 0.6$ & 0.388 \\
CRP $(\mathrm{mg} / \mathrm{L})$ & $83.6 \pm 34$ & $60 \pm 31$ & 0.09 \\
CRP/MPV & $7.6 \pm 3.3$ & $5.3 \pm 2.8$ & 0.067 \\
Serum IL-10 $(\mathrm{pg} / \mathrm{ml})$ & $330.7 \pm 198$ & $267 \pm 199$ & 0.304 \\
Salivary IL-10 $(\mathrm{pg} / \mathrm{ml})$ & $278 \pm 185$ & $203 \pm 137$ & 0.304 \\
\hline
\end{tabular}

MPV: mean platelet volume; CRP: C-reactive protein; IL-10: interleukin 10.

significantly lower platelet count compared to the control group $(P=0.012)$. Septic neonates had significantly higher MPV (mean $11.2 \pm 0.9$ vs. $8.6 \pm 0.4 \mathrm{fL}, P<0.001$ ), CRP (mean $78.2 \pm 34$ vs. $3.3 \pm 1.7 \mathrm{mg} / \mathrm{L}, P<0.001$ ), and $\mathrm{CRP} / \mathrm{MPV}$ ratio ( $7.08 \pm 3.3$ vs. $0.4 \pm 0.2, P<0.001)$. Both serum and salivary IL-10 were also significantly higher in septic neonates (mean $316 \pm 198$ vs. $23.7 \pm 14 \mathrm{pg} / \mathrm{ml}, P<0.001$ ) and (mean $220 \pm$ 150 vs. $18 \pm 9 \mathrm{pg} / \mathrm{ml}, P<0.001$ ), respectively. There was no significant difference in total leucocyte count.

3.4. Comparison of Salivary and Serum IL-10, CRP/MPV Ratio, and Other Markers in Blood Culture Positive and Negative Septic Cases. In septic neonates, there were no significant differences in the results of MPV, CRP, CRP/MPV ratio, serum, and salivary IL-10 between blood culture positive and negative septic cases (Table 2). 
TABLE 3: ROC curves for salivary and serum IL-10, MPV, and CRP/MPV ratio to predict late-onset sepsis.

\begin{tabular}{|c|c|c|c|c|c|c|c|c|}
\hline Parameter & AUC & SE & $95 \% \mathrm{CI}$ & Cutoff value & Sensitivity (\%) & Specificity (\%) & PPV (\%) & NPV (\%) \\
\hline MPV (fL) & 0.999 & 0.001 & $0.99-1$ & $\geq 9.2$ & 100 & 94.3 & 94.6 & 100 \\
\hline CRP/MPV ratio & 1 & 0.000 & $1-1$ & $\geq 0.90$ & 100 & 97.1 & 97.2 & 100 \\
\hline Serum IL-10 (pg/ml) & 0.97 & 0.024 & $0.92-1$ & $\geq 33.6$ & $97.1 \%$ & 80 & 82.9 & 96.6 \\
\hline Salivary IL-10 (pg/ml) & 0.994 & 0.005 & $0.98-1$ & $\geq 31$ & 97.1 & 94.3 & 94.4 & 97.1 \\
\hline
\end{tabular}

MPV: mean platelet volume; CRP: C-reactive protein; IL-10: interleukin 10; PPV: positive predictive values; NPV: negative predictive value.
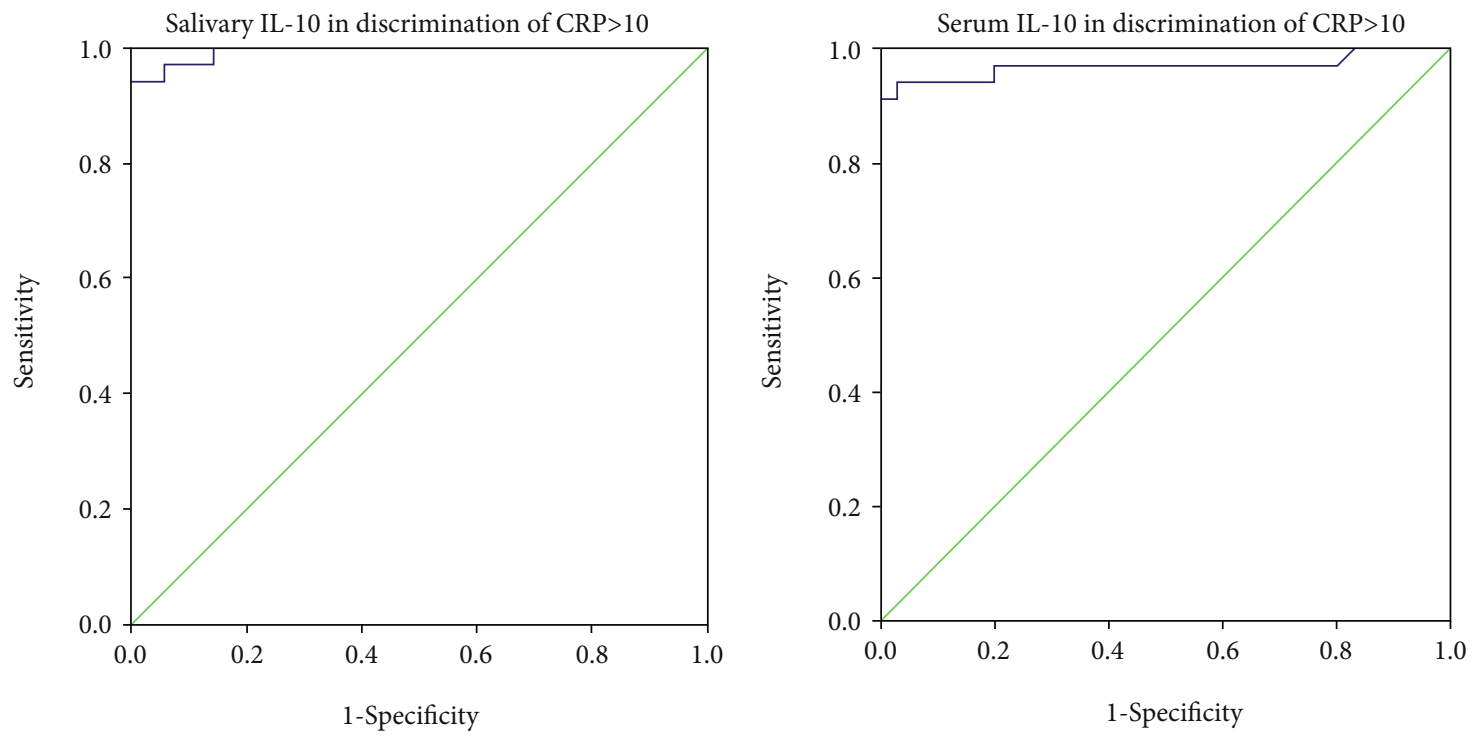

FIgURE 2: Salivary and serum IL-10 in discrimination of serum CRP values $>10 \mathrm{mg} / \mathrm{L}$.

3.5. ROC Curve Analysis for Salivary and Serum IL-10, MPV, and CRP/MPV to Predict Late-Onset Sepsis. MPV showed a sensitivity of $100 \%$ and specificity of $94.3 \%$ at a cutoff value $\geq 9.2 \mathrm{fL}$. CRP/MPV ratio showed the highest sensitivity of $100 \%$ and specificity of $97.1 \%$ at a cutoff value $\geq 0.90$. Serum IL-10 at a cutoff value $\geq 33.6$ showed sensitivity of $97.1 \%$, specificity $80 \%$, PPV $82.9 \%$, and NPV 96.6\%. Salivary IL-10 at a cutoff value $\geq 31$ showed very high sensitivity of $97.1 \%$, specificity 94.3\%, PPV 94.4\%, and NPV 97.1\% (Table 3).

\subsection{Salivary and Serum IL-10 to Discriminate Serum CRP} Values $>10 \mathrm{mg} / \mathrm{L}$. We also tested the ROC curves for serum and salivary IL-10 and their abilities to discriminate serum CRP values $>10 \mathrm{mg} / \mathrm{L}$. ROC curves showed that both serum and salivary IL-10 have excellent ability to detect serum CRP values $>10 \mathrm{mg} / \mathrm{L}$ in septic neonates (Figure 2).

3.7. Correlation between Salivary and Serum IL-10 and Other Laboratory Markers. We also tested the correlation between salivary and serum IL-10 and other laboratory markers. There was a significant positive correlation between salivary IL-10 with both CRP $(r=0.356, P<0.05)$ and $\mathrm{CRP} / \mathrm{MPV}$ ratio $(r=0.390, P<0.05)$. Also, there was a significantly positive correlation between serum IL-10 with TLC $(r=0.374, P<0.05)$, CRP $(r=0.39, P<0.05)$, and CRP/MPV ratio $(r=0.424, P<0.05)$ Table 4 .
TABLE 4: Correlation between salivary and serum IL-10 and other laboratory markers.

\begin{tabular}{lcccc}
\hline \multirow{2}{*}{ Variables } & \multicolumn{2}{c}{ Salivary IL-10 } & \multicolumn{2}{c}{ Serum IL-10 } \\
& $R$ & $P$ value & $R$ & $P$ value \\
\hline TLC & -0.08 & 0.649 & 0.374 & $0.027 *$ \\
MPV & 0.201 & 0.246 & -0.284 & 0.099 \\
CRP & 0.356 & $0.036 *$ & 0.39 & $0.021 *$ \\
CRP/MPV ratio & 0.390 & $0.006 *$ & 0.424 & $0.011 *$ \\
\hline
\end{tabular}

TLC: total leucocytic count; MPV: mean platelet volume; CRP: C-reactive protein.

\section{Discussion}

Neonatal sepsis is a major public health problem and the third leading cause of neonatal mortality. Although the great advances in neonatal medical care, many challenges remain in the diagnosis of neonatal sepsis. In this study, we evaluated the diagnostic value of salivary IL-10 as a noninvasive marker as well as serum IL-10, CRP, MPV, and CRP/MPV ratio in early diagnosis of late-onset neonatal sepsis in fullterm neonates.

In high-risk infants, mortality rates in late-onset sepsis reach up to $18 \%$ [40]. Sick hospitalized neonates require laboratory tests and repeated blood sampling which exposed 
these fragile populations to the risk of pain, infection, cardiorespiratory instability, and anemia. There is an urgent need for a reliable and accurate noninvasive diagnostic biomarker for the early diagnosis of late-onset neonatal sepsis.

Salivary testing is a noninvasive alternate to blood for diagnosis and monitoring common neonatal morbidities, such as infections, and could vastly improve the care for neonates and positively affect their long-term clinical outcomes.

To the best of our knowledge, our study investigates, for the first time, salivary IL-10 as a noninvasive marker for the diagnosis of late-onset sepsis in full-term neonates. In our study, a salivary IL-10 value was significantly different between septic and control neonates and showed very high sensitivity and specificity. Sesso et al. [41] reported that salivary cytokines including salivary IL-10 could be detected in full-term neonates within the first hours after birth, and their levels decreased after 3 months. Recently, Chen et al. [18] investigated the relationship between salivary cytokines and neonatal bacterial infection in premature neonates; they found that the combination of blood sugar and salivary IL-6 could detect bacterial infection in preterm neonates.

In our study, the mean serum IL-10 was also significantly different between the septic and control neonates. Wang et al. [12], in just-published meta-analysis, found that IL-10 is a useful biomarker in the early diagnosis of neonatal sepsis. Its sensitivity, specificity, and diagnostic ability are excellent.

Other studies showed that the optimal cutoff value of IL-10 in the diagnosis of neonatal sepsis ranged from 3.8 to $49 \mathrm{pg} / \mathrm{ml}$. The difference may be related to the different detection methods of IL-10 expression [9, 10, 42-44]. Zeitoun et al. [9] found the average expression of IL-10 in the late-onset neonatal sepsis group was $198.3 \mathrm{pg} / \mathrm{ml}$. Furthermore, the expression level of IL-10 was positively correlated with the severity of neonatal sepsis. The more severe cases of neonatal sepsis had higher expression levels of IL-10, especially in low birth weight infants with sepsis [44-46].

In our study, there was no significant difference in the mean of salivary and serum IL-10 in culture-positive and culture-negative neonates. Zeitoun et al. [9] reported the same observation on serum IL-10 in culture-positive cases with a mean of $189.3 \mathrm{pg} / \mathrm{ml}$ compared with a mean of $198.3 \mathrm{pg} / \mathrm{ml}$ in culture-negative cases.

In our study, salivary and serum IL-10 showed a positive correlation with CRP and CRP/MPV ratio in septic neonates. Unexpectedly, Khaertynov et al. [8] observed no correlation between serum IL-10 and CRP in their study. This could return to different characteristics in the study population in the two studies.

Despite the detection of new markers, CRP is still one of the most expressively used acute phase reactants in the diagnosis of neonatal sepsis. Our study revealed a significant difference between septic and control neonates. In agreement with our results, other researchers observed the same findings [3,15-17]. Also, salivary CRP was investigated as a noninvasive marker for the diagnosis of neonatal sepsis [15-17].
Our study showed that MVP was significantly different between septic and the control neonates. In support to our results, just published 2 meta-analyses reported significantly higher MPV in newborns with sepsis compared to healthy controls [22, 23]. Very close to our results, Milas et al. [22], in their meta-analysis, reported an optimal cutoff point of $9.28 \mathrm{fL}$ for differentiating septic neonates from healthy controls.

Our study also investigates the value of CRP/MPV ratio in diagnosis of late-onset neonatal sepsis in full-term neonates. We found that CRP/MPV ratio was significantly higher in the sepsis group compared to the control group. CRP/MPV ratio showed a very high ability in predicting septic neonates. We believe that the CRP/MPV ratio may offer an advantage in the early diagnosis of neonatal sepsis which could be superior to either CRP or MPV when evaluated alone. There is only one study in the literature evaluating the CRP/MPV ratio in children with pneumonia suggesting that the CRP/MPV ratio might be used in differentiating bacterial from viral pneumonia and prediction of complications [28]. Recently, CRP/albumin ratio is used as a potential marker for gram-negative bacteremia in late-onset neonatal sepsis [29].

\section{Conclusion}

The current study shows for the first time that both salivary IL-10 and CRP/MPV ratio showed statistically significant differences between neonates with late-onset sepsis and controls. CRP/MPV is an easily calculated ratio which could be used as a simple and accurate marker for the diagnosis of late-onset neonatal sepsis. Salivary IL-10 could serve as potential noninvasive biomarker for the diagnosis of lateonset sepsis in full-term neonates.

\section{Data Availability}

The data that support the findings of this study are available on request from the corresponding author. The data are not publicly available due to privacy or ethical restrictions.

\section{Conflicts of Interest}

The authors declare that they have no conflicts of interest.

\section{Authors' Contributions}

A.O. has substantially contributed to the conception and design of the study, acquisition, analysis and interpretation of the data, drafting the paper, and supervising the whole work. H.S. has substantially contributed to the acquisition, analysis, and interpretation of the data. M.O. performed the laboratory part of this study, substantially contributed to interpretation of the data and revised the article critically for important intellectual content. A.K. and A.R.R. have substantially contributed to the conception and design of the study, acquisition and interpretation of the data, and revised the article critically for important intellectual content. S.E. has substantially contributed to the conception 
and design of the study, interpretation of the data, revised the article critically for important intellectual content, and supervised the whole work. All authors approved the final version of the manuscript submitted. Ahmed Omran and Hazem Sobh contributed equally to this work.

\section{References}

[1] J. E. Lawn, H. Blencowe, S. Oza et al., "Every newborn: progress, priorities, and potential beyond survival," The Lancet, vol. 384, no. 9938, pp. 189-205, 2014.

[2] L. Liu, S. Oza, D. Hogan et al., "Global, regional, and national causes of child mortality in 2000-13, with projections to inform post-2015 priorities: an updated systematic analysis," The Lancet, vol. 385, no. 9966, pp. 430-440, 2015.

[3] N. Hofer, E. Zacharias, W. Müller, and B. Resch, "An update on the use of C-reactive protein in early-onset neonatal sepsis: current insights and new tasks," Neonatology, vol. 102, no. 1, pp. 25-36, 2012.

[4] K. Hendricks-Munoz, J. Xu, and P. Mally, "Biomarkers for neonatal sepsis: recent developments," Research and Reports in Neonatology, vol. 4, pp. 157-168, 2014.

[5] C. Hawrylowicz and A. O'Garra, "Potential role of interleukin10 -secreting regulatory T cells in allergy and asthma," Nature Reviews Immunology, vol. 5, no. 4, pp. 271-283, 2005.

[6] K. W. Moore, R. de Waal Malefyt, R. L. Coffman, and A. O'Garra, "Interleukin-10 and the interleukin-10 receptor," Annual Review of Immunology, vol. 19, no. 1, pp. 683-765, 2001.

[7] A. O'Garra, F. J. Barrat, A. G. Castro, A. Vicari, and C. Hawrylowicz, "Strategies for use of IL-10 or its antagonists in human disease," Immunological Reviews, vol. 223, no. 1, pp. 114-131, 2008.

[8] K. S. Khaertynov, S. V. Boichuk, S. F. Khaiboullina et al., "Comparative assessment of cytokine pattern in early and late onset of neonatal sepsis," Journal of Immunology Research, vol. 2017, Article ID 8601063, 8 pages, 2017.

[9] A. A. Zeitoun, S. S. Gad, F. M. Attia, A. S. Abu Maziad, and E. F. Bell, "Evaluation of neutrophilic CD64, interleukin 10 and procalcitonin as diagnostic markers of early- and lateonset neonatal sepsis," Scandinavian Journal of Infectious Diseases, vol. 42, no. 4, pp. 299-305, 2010.

[10] C. Sherwin, R. Broadbent, S. Young et al., "Utility of interleukin-12 and interleukin-10 in comparison with other cytokines and acute-phase reactants in the diagnosis of neonatal sepsis," American Journal of Perinatology, vol. 25, no. 10, pp. 629-636, 2008.

[11] Y. A. Leal, J. Álvarez-Nemegyei, A. I. Lavadores-May, J. L. Girón-Carrillo, R. Cedillo-Rivera, and J. R. Velazquez, "Cytokine profile as diagnostic and prognostic factor in neonatal sepsis," The Journal of Maternal-Fetal \& Neonatal Medicine, vol. 32, no. 17, pp. 2830-2836, 2019.

[12] Q. Wang, G. Peng, L. Gan, Z. Deng, L. Zeng, and J. Deng, "The value of interleukin-10 in the early diagnosis of neonatal sepsis," Pediatric Critical Care Medicine, vol. 22, no. 9, pp. e492-e501, 2021.

[13] A. Iyengar and J. L. Maron, "Detecting infection in neonates: promises and challenges of a salivary approach," Clinical Therapeutics, vol. 37, no. 3, pp. 523-528, 2015.

[14] A. Omran, M. Ali, M. H. S. Mohammad, and O. Zekry, "Salivary $\mathrm{C}$-reactive protein and mean platelet volume in diagnosis of late-onset neonatal pneumonia," The Clinical Respiratory Journal, vol. 12, no. 4, pp. 1644-1650, 2018.

[15] A. Omran, A. Maaroof, M. H. S. Mohammad, and A. Abdelwahab, "Proteina $C$ reativa salivar, volume medio de plaquetas e proporçao de neutrofilos/linfocitos como marcadores de diagnostico de sepse neonatal," Jornal de Pediatria (Versão em Português), vol. 94, no. 1, pp. 82-87, 2018.

[16] S. Datla, S. Kitchanan, and G. Sethuraman, "Diagnostic reliability of salivary C-reactive protein as an alternative noninvasive biomarker of neonatal sepsis," Indian Pediatrics, vol. 58, no. 8, pp. 745-748, 2021.

[17] A. M. Tosson, D. Koptan, R. Abdel Aal, and M. Abd Elhady, "Evaluation of serum and salivary C-reactive protein for diagnosis of late- onset neonatal sepsis: a single center cross-sectional study," Jornal de Pediatria, 2021.

[18] I.-L. Chen, H. C. Huang, M. C. Ou-Yang, F. S. Chen, M. Y. Chung, and C. C. Chen, "A novel method to detect bacterial infection in premature infants: using a combination of inflammatory markers in blood and saliva," Journal of Microbiology, Immunology and Infection, vol. 53, no. 6, pp. 892-899, 2020.

[19] I. Berka, P. Korček, and Z. Straňák, "C-reactive protein, interleukin-6, and procalcitonin in diagnosis of late-onset bloodstream infection in very preterm infants," Journal of the Pediatric Infectious Diseases Society, 2021.

[20] C. Aydemir, H. Aydemir, F. Kokturk, C. Kulah, and A. G. Mungan, "The cut-off levels of procalcitonin and C-reactive protein and the kinetics of mean platelet volume in preterm neonates with sepsis," BMC Pediatrics, vol. 18, no. 1, pp. 112, 2018.

[21] S. B. Hanaganahalli, S. Sreeram, M. Bompada, S. K. Kuppannagari, P. K. Suresh, and C. S. Philipose, "Is MPV a predictive marker for neonatal sepsis? A pilot study," Journal of Pediatric Hematology/Oncology, vol. 40, no. 7, pp. 548-552, 2018.

[22] G.-P. Milas, V. Karageorgiou, and I. Bellos, "Mean platelet volume and neonatal sepsis: a systematic review and metaanalysis of diagnostic accuracy," The Journal of MaternalFetal \& Neonatal Medicine, pp. 1-13, 2021.

[23] J. Wang, Z. Wang, M. Zhang, Z. Lou, J. Deng, and Q. Li, "Diagnostic value of mean platelet volume for neonatal sepsis," Medicine, vol. 99, no. 32, p. e21649, 2020.

[24] S. Ball, J. A. Dennis, G. Bedanie, and K. Nugent, "Relation between mean platelet volume and C-reactive protein," Baylor University Medical Center Proceedings, vol. 33, pp. 163-168, 2020.

[25] J.-H. Lee, K. Y. Kwon, S. Y. Yoon, H. S. Kim, and C. S. Lim, "Characteristics of platelet indices, neutrophil-to-lymphocyte ratio and erythrocyte sedimentation rate compared with $\mathrm{C}$ reactive protein in patients with cerebral infarction: a retrospective analysis of comparing haematological parameters and $\mathrm{C}$ reactive protein," BMJ Open, vol. 4, no. 11 , article e006275, 2014.

[26] J.-H. Lee, S. Y. Yoon, H. S. Kim, and C. S. Lim, "Characteristics of the mean platelet volume, neutrophil to lymphocyte ratio, and C-reactive protein compared to the procalcitonin level in pneumonia patients," Platelets, vol. 26, no. 3, pp. 278-280, 2015.

[27] A. R. Moon, D. H. Choi, S. Y. Jahng et al., "High-sensitivity Creactive protein and mean platelet volume as predictive values after percutaneous coronary intervention for long-term clinical outcomes: a comparable and additive study," Blood Coagulation \& Fibrinolysis, vol. 27, no. 1, pp. 70-76, 2016. 
[28] M. Bekdas, S. B. Goksugur, E. G. Sarac, M. Erkocoglu, and F. Demircioglu, "Neutrophil/lymphocyte and C-reactive protein/mean platelet volume ratios in differentiating between viral and bacterial pneumonias and diagnosing early complications in children," Saudi Medical Journal, vol. 35, no. 5, pp. 442-447, 2014.

[29] H. Güneş, S. Yurttutan, M. Çobanuşağı, and A. Doğaner, "CRP/albumin ratio: a promising marker of gram-negative bacteremia in late-onset neonatal sepsis," Turkish Archives of Pediatrics, vol. 56, p. 32, 2021.

[30] E. Can, Ş. Hamilcikan, and C. Can, "The value of neutrophil to lymphocyte ratio and platelet to lymphocyte ratio for detecting early-onset neonatal sepsis," Journal of Pediatric Hematology/Oncology, vol. 40, no. 4, pp. e229-e232, 2018.

[31] B. Karabulut and S. O. Alatas, "Diagnostic value of neutrophil to lymphocyte ratio and mean platelet volume on early onset neonatal sepsis on term neonate," Journal of Pediatric Intensive Care, vol. 10, no. 2, pp. 143-147, 2021.

[32] T. Li, M. Zhang, Z. Xu et al., "Association of neutrophil-lymphocyte ratio and the presence of neonatal sepsis," Journal of Immunology Research, vol. 2020, Article ID 7650713, 8 pages, 2020.

[33] S. K. Panda, M. K. Nayak, S. Rath, and P. Das, "The utility of the neutrophil-lymphocyte ratio as an early diagnostic marker in neonatal sepsis," Cureus, vol. 13, 2021.

[34] B. Karabulut and B. C. Arcagok, "Platelet to lymphocyte ratio in neonates: a predictor of early onset neonatal sepsis," Mediterranean Journal of Hematology and Infectious Diseases, vol. 11, no. 1, 2019.

[35] U. Töllner, "Early diagnosis of septicemia in the newborn," European Journal of Pediatrics, vol. 138, no. 4, pp. 331-337, 1982.

[36] B. Dawson et al., Basic \& Clinical Biostatistics vol. 4, Lange Medical Books/McGraw-Hill New York, 2004.

[37] R. S. Baltimore, "Neonatal sepsis," Pediatric Drugs, vol. 5, no. 11, pp. 723-740, 2003.

[38] F. Chiappelli, F. J. I. Iribarren, and P. Prolo, "Salivary biomarkers in psychobiological medicine," Bioinformation, vol. 1, no. 8, pp. 331-334, 2006.

[39] J. A. Dietz, K. L. Johnson, H. C. Wick, D. W. Bianchi, and J. L. Maron, "Optimal techniques for mRNA extraction from neonatal salivary supernatant," Neonatology, vol. 101, no. 1, pp. 55-60, 2012.

[40] S. Mehr, J. L. Sadowsky, L. W. Doyle, and J. Carr, "Sepsis in neonatal intensive care in the late 1990s," Journal of Paediatrics and Child Health, vol. 38, no. 3, pp. 246-251, 2002.

[41] M. L. T. Sesso, M. C. L. Borges, V. P. L. Ferriani, V. R. GeraldoMartins, D. B. R. Rodrigues, and R. D. Nogueira, "Prospective evaluation of cytokine in saliva of preterm and fullterm neonates," Immunobiology, vol. 219, no. 11, pp. 830-835, 2014.

[42] P. C. Ng, K. Li, K. M. Chui et al., "IP-10 is an early diagnostic marker for identification of late-onset bacterial infection in preterm infants," Pediatric Research, vol. 61, no. 1, pp. 93-98, 2007.

[43] A. M. Tosson, K. Glaser, T. Weinhage et al., "Evaluation of the S100 protein A12 as a biomarker of neonatal sepsis," The Journal of Maternal-Fetal \& Neonatal Medicine, vol. 33, no. 16, pp. 2768-2774, 2020.

[44] Q. Ye, L. Z. du, W. X. Shao, and S. Q. Shang, "Utility of cytokines to predict neonatal sepsis," Pediatric Research, vol. 81, no. 4 , pp. $616-621,2017$.
[45] L. Bender, J. Thaarup, K. Varming, H. Krarup, S. EllermannEriksen, and F. Ebbesen, "Early and late markers for the detection of early-onset neonatal sepsis," Danish Medical Bulletin, vol. 55, pp. 219-223, 2008.

[46] S. S. Schüller, L. Wisgrill, E. Herndl et al., "Pentoxifylline modulates LPS-induced hyperinflammation in monocytes of preterm infants _in vitro_," Pediatric Research, vol. 82, no. 2, pp. 215-225, 2017. 